\title{
The Motor Neuron-Like Cell Line NSC-34 and Its Parent Cell Line N18TG2 Have Glycogen that is Degraded Under Cellular Stress
}

\author{
${\text { Brigitte Pfeiffer-Guglielmi }{ }^{1} \mathbb{D} \cdot \text { Ralf-Peter Jansen }}^{1}$
}

Received: 23 October 2020 / Revised: 7 February 2021 / Accepted: 8 March 2021 / Published online: 30 March 2021

(c) The Author(s) 2021

\begin{abstract}
Brain glycogen has a long and versatile history: Primarily regarded as an evolutionary remnant, it was then thought of as an unspecific emergency fuel store. A dynamic role for glycogen in normal brain function has been proposed later but exclusively attributed to astrocytes, its main storage site. Neuronal glycogen had long been neglected, but came into focus when sensitive technical methods allowed quantification of glycogen at low concentration range and the detection of glycogen metabolizing enzymes in cells and cell lysates. Recently, an active role of neuronal glycogen and even its contribution to neuronal survival could be demonstrated. We used the neuronal cell lines NSC-34 and N18TG2 and could demonstrate that they express the key-enzymes of glycogen metabolism, glycogen phosphorylase and glycogen synthase and contain glycogen which is mobilized on glucose deprivation and elevated potassium concentrations, but not by hormones stimulating cAMP formation. Conditions of metabolic stress, namely hypoxia, oxidative stress and $\mathrm{pH}$ lowering, induce glycogen degradation. Our studies revealed that glycogen can contribute to the energy supply of neuronal cell lines in situations of metabolic stress. These findings shed new light on the so far neglected role of neuronal glycogen. The key-enzyme in glycogen degradation is glycogen phosphorylase. Neurons express only the brain isoform of the enzyme that is supposed to be activated primarily by the allosteric activator AMP and less by covalent phosphorylation via the cAMP cascade. Our results indicate that neuronal glycogen is not degraded upon hormone action but by factors lowering the energy charge of the cells directly.
\end{abstract}

Keywords Neuronal cell lines $\cdot$ Glycogen $\cdot$ Glycogen phosphorylase isozymes $\cdot$ Metabolic stress

\section{Introduction}

Glycogen represents the only brain energy reserve though its quantities are small compared to muscle and liver [1]. Because cerebral glycogen is predominantly located in astrocytes, its possible functions have been attributed for decades to these cells with the consensus that glycogen is an emergency fuel reserve for conditions of physiological or pathological stress. However, more recent studies have shown that glycogen serves a dynamic role also in normal brain metabolism, e.g. in neurotransmission, learning and memory consolidation, and in sleep [2-5].

A physiological role of glycogen in central nervous system neurons has long been denied though they express

Brigitte Pfeiffer-Guglielmi

brigitte.pfeiffer@uni-tuebingen.de

1 Interfaculty Institute for Biochemistry, University of Tübingen, Auf der Morgenstelle 34, 72076 Tübingen, Germany glycogen synthase (GS) and have the potential to synthesize glycogen under pathological conditions [6]. In neurons of the peripheral nervous system and in spinal motor neurons, the intense immunoreactvity for glycogen phosphorylase brain isoform (GPBB) made the presence of its substrate highly probable $[7,8]$. The current view on neuronal glycogen changed with the availability of highly sensitive methods allowing the quantitative determination of glycogen in cortical neuronal cultures [9] as well as the detection of the glycogen metabolizing enzymes at the protein and mRNA levels [10]. Though the glycogen content of cortical neurons only mounts up to about $1 / 10$ of that of astrocytes, it could be demonstrated that neurons have an active glycogen metabolism that contributes to tolerance to hypoxia [9]. These findings have drawn new attention to the role of neuronal glycogen in health and disease [11-13].

Under these aspects, the high immunoreactivity for GPBB in peripheral neurons and spinal motor neurons may be an indicator for an active glycogen metabolism in these cells. The high vulnerability of motor neurons and their 
involvement in neurodegenerative diseases like amyotrophic lateral sclerosis make these cells a highly probable candidate for glycogen utilization. Metabolic studies like glycogen determination under different metabolic conditions, however, require cell culture systems with high yields and purity. Peripheral neurons like dorsal root ganglion neurons as well as spinal motor neurons can be cultured, the latter even in high purity, but the cell yields are too low for metabolic studies. Neuronal cell lines, in contrast, would fulfill both conditions. NSC-34 is a hybrid cell line generated by the fusion of mouse embryonic motor neuron-enriched spinal cord cells with mouse neuroblastoma N18TG2 [14]. This cell line is a relevant model for the study of motor neuron biology and expresses many motor neuron-like properties (for overview, see [14-16]). NSC-34 cultures comprise two morphologically distinct populations: neuroblastic cells with minimal projections and cells that undergo differentiation and have long processes [15]. Differentiation can be achieved by cultivation under low serum concentration which is accompanied by high cell loss. Several authors use differentiated cells because some properties are only expressed in differentiated cells.

If NSC-34 had glycogen and the glycogen metabolizing machinery, these properties could originate from the primary parent cell (spinal cord motor neurons) or the parent tumor cell line (neuroblastoma). If NSC-34, but not N18TG2 had glycogen metabolizing properties, NSC-34 would be an ideal model for investigating motor neuronal glycogen. If N18TG2 had an active glycogen metabolism, too, this could mask the effects of the motor neuron glycogen metabolism, especially if there are no major quantitative differences in glycogen content and enzyme profiles. In this case, two conclusions are possible: 1) An active glycogen metabolism is relevant for motor neurons and tumor cells or, going further, (2) glycogen metabolism is of importance for neurons in general.

In this study, we first investigated whether NSC-34 and N18TG2 contain glycogen and express the key enzymes of glycogen metabolism, GS and GP. Next, we looked for factors influencing glycogen metabolism in order to get insight into the metabolic regulation of glycogen degradation. The contribution of neuronal glycogen to tolerance of hypoxia stress makes glycogen a possible player in conditions of metabolic stress in general. We therefore examined glycogen mobilization in NSC-34 and N18TG2 cell lines under conditions of hypoxia, oxidative stress and $\mathrm{pH}$ lowering.

The enzyme catalyzing the rate-limiting step in glycogen degradation is glycogen phosphorylase. GP exists in three isoforms named according to the tissues they dominate in: brain, skeletal muscle, and liver. Astrocytes express GPBB and glycogen phosphorylase muscle isoform (GPMM) in equal amounts and perfect colocalization [6]. Neurons express only GPBB [7, 8]. Consequently, glycogen degradation in neurons must be attributed to GPBB and metabolic effects on glycogen content found in neurons should also be found in astrocytes because of their GPBB fraction. We therefore included astrocyte primary cultures (APC) in our stress experiments. In addition, we investigated whether siRNA knockdown of GPBB blocks a possible stress-induced glycogen breakdown.

\section{Materials and Methods}

\section{Cell Culture}

The NSC-34 cell line was purchased from Cedarline (Burlington, Ontario, Canada) via tebu-bio (Offenbach, Germany). Cells were cultured in Dulbecco's Modified Eagle's medium (DMEM) $/ 10 \%$ fetal calf serum (FCS)/25\% glucose with penicillin and streptomycin. For studies with differentiated cells, cultures were switched to a medium with low FCS concentration (DMEM/Ham's F 12 1:1/Eagle's medium with $1 \%$ non-essential amino acid solution/3\% FCS/25 mM glucose with penicillin and streptomycin) [15]. The maximum number of passages was 34. The N18TG2 cell line was purchased from the German Collection of Microorganisms and Cell Cultures (DSMZ, Braunschweig, Germany). Cells were cultured in DMEM/10\% $\mathrm{FCS} / 100 \mu \mathrm{M}$ thioguanine $/ 25 \mathrm{mM}$ glucose. The maximum number of passages was 20 . Both cell lines were cultured in $60 \mathrm{~mm}$ plates at $10 \% \mathrm{CO}_{2}$ and $37^{\circ} \mathrm{C}$ until confluency.

Neuronal and astrocyte primary cultures were prepared as described [10].

All experiments involving animals were carried out according to the law of animal experimentation issued by the German parliament ("Tierschutzgesetz") and to the European Communities Council Directive.

\section{SiRNA Knockdown}

NSC-34 cells were cultured to $80 \%$ confluency and transfected with ON-TARGET plus siRNA (Dharmacon) targeting the GPBB sequences as described [17]. FUGENE HD Transfection Reagent (Promega, Madison, Wi, USA) was used according to the manufacturer's protocol. siRNAs were applied in a concentration of $25 \mathrm{nM}$ in OptiMEM medium (Gibco). APC were transfected analogously in the second week in culture. $24 \mathrm{~h}$ post transfection, medium was changed to culture medium and cells were cultured for 5 days. Negative controls were performed by applying a non-targeting siRNA (NT siRNA; Dharmacon). Knockdown was controlled by Western blotting. 


\section{Western Blotting}

Supernatants of lysates from NSC-34, N18TG2, NPC and APC were prepared as described [10].Supernatants of lysates from motor neuron cultures were prepared in a buffer containing $50 \mathrm{mM}$ Tris/ $\mathrm{HCl} \mathrm{pH} 7.4,150 \mathrm{mM} \mathrm{NaCl}$, $1 \%$ Triton X-100 and 2 mM EDTA and were a kind gift of S. Jablonka (Würzburg). Western blotting was performed as described [10]. In addition to the peroxidase/chemiluminescence detection system, we applied IRDye ${ }^{\circledR} 680$ RD goat anti-rabbit antibody (LI-COR-Biosciences, Bad Homburg, Germany). Rabbit antisera against GP BB and GP MM were prepared as described [6]. Rabbit monoclonal antibody against GS ( $\mathrm{mAb}$ 15B1) was purchased from Cell signaling Technology (Danvers, Mas., USA).

\section{Protein Determination}

For protein determination we used a microtiter plate Bradford assay with Roti-Quant reagent (Roth, Karlsruhe, Germany) and bovine serum albumin as standard. The alkaline $\mathrm{pH}$ of the lysates did not interfere with the assay because the samples were highly diluted for the test, and the strongly acidic reagent was added in surplus.

\section{Glycogen Determination}

Glycogen content of cell cultures was determined applying a method described [9] in combination with a fluorometric assay [18]. After incubation of the cells under the relevant metabolic conditions, the culture medium was removed and the cells rapidly frozen and stored at $-80^{\circ} \mathrm{C}$. For analysis, cells were scraped off the plates in a volume of $400 \mu \mathrm{l}$ of $30 \% \mathrm{KOH}$ and the lysate incubated for $15 \mathrm{~min}$ at $100{ }^{\circ} \mathrm{C}$. After taking an aliquot for protein determination, glycogen was precipitated in the lysate by the addition of ethanol to a concentration of $65 \%(\mathrm{v} / \mathrm{v})$ overnight at $-20{ }^{\circ} \mathrm{C}$. After centrifugation at $12000 \mathrm{~g}$ for $10 \mathrm{~min}$ at $4{ }^{\circ} \mathrm{C}$, pellets were airdried overnight at room temperature. Thereafter, glycogen was digested in a volume of $200 \mu \mathrm{l}$ of $50 \mathrm{mM}$ acetate buffer $\mathrm{pH} 4.8$ with $1 \mathrm{U}$ of amyloglucosidase $\left(1 \mathrm{~h}, 37^{\circ} \mathrm{C}\right)$. Then, glucose was determined with a fluorometric microplate assay under the following conditions: $20 \mu \mathrm{l}$ of the amyloglucosidase digest were incubated for $30 \mathrm{~min}$ at $37^{\circ} \mathrm{C}$ with $80 \mu \mathrm{l}$ of $100 \mu \mathrm{M}$ triethanolamine buffer $\mathrm{pH} 7.6$ containing $1 \mathrm{mM} \mathrm{MgCl}{ }_{2}, 1 \mathrm{mM}$ ATP, $100 \mu \mathrm{M}$ NADP, $10 \mu \mathrm{M}$ resazurin, $0.1 \mathrm{U} / \mathrm{ml}$ glucose-6-phosphate dehydrogenase, $0.2 \mathrm{U} / \mathrm{ml}$ diaphorase and $12 \mathrm{U} / \mathrm{ml}$ hexokinase. Fluorescence intensity was measured at an excitiation wavelength of $530 \mathrm{~nm}$ and an emission wavelength of $590 \mathrm{~nm}$. Glycogen was expressed as nmol glucose residues and normalized to the protein content of the culture plates.

\section{Metabolic Studies}

For studying the influence of various parameters on the glycogen content, the cells were cultured to confluency and then switched to the conditions of the relevant experiment (for details, see Results).

To study the glycogen content under conditions of cellular stress, confluent cultures were switched to DMEM/5 mM glucose for $4 \mathrm{~h}$ in order to mimic conditions closer to the metabolic situation in vivo. To examine the glycogen content under conditions of reduced oxygen concentration (hypoxia stress), cells were incubated in an oxygen-regulated incubator with $1 \% \mathrm{O}_{2}, 5 \% \mathrm{CO}_{2}$ and $94 \% \mathrm{~N}_{2}$ at $37{ }^{\circ} \mathrm{C}$ for $4 \mathrm{~h}$. Control cultures were kept under normoxic conditions $\left(21 \% \mathrm{O}_{2}\right)$. To study the influence of oxidative stress, hydrogen peroxide was added to the medium to a concentration of $500 \mu \mathrm{M}$ and the cells kept for 30,60 or $120 \mathrm{~min}$, respectively, under these conditions. To examine the influence of lower $\mathrm{pH}$ values on the glycogen content (acidic stress), cultures were switched to $20 \mathrm{mM}$ HEPES/Earle's salts $/ 5 \mathrm{mM}$ glucose $\mathrm{pH} 7.4$ (control) or 7.0 and 6.5 and incubated on a $37{ }^{\circ} \mathrm{C}$ water bath for $30 \mathrm{~min}$.

After the experiments, the medium was removed, the plates quickly frozen at $-80^{\circ} \mathrm{C}$ and stored until glycogen determination.

\section{Cell Viability}

Trypan blue exclusion test was applied to determine cell viability.

\section{Statistics}

Data are expressed as individual values and include determinations made in one experiment with $n=3$ to 6 . At least three replicates were made for one experiment. $p$ values were obtained by student's unpaired two-tailed t-test using the GraphPad Prism software.

\section{Results}

\section{NSC-34 and N18TG2 Cell Lines Express Glycogen Phosphorylase and Glycogen Synthase, the Key-Enzymes of Glycogen Metabolism, and Contain Glycogen}

In order to investigate whether the neuronal cell lines NSC34 and N18TG2 have the enzymatic machinery to synthesize and degrade glycogen, we performed Western blotting. Both cell lines express GPBB and GS (Fig. 1a,b). Differentiation of NSC-34 does not influence the expression patterns of the 
a

NPC NSC-34 N18TG2 motoneurons

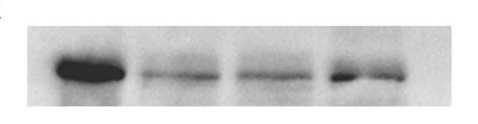

GPBB

b

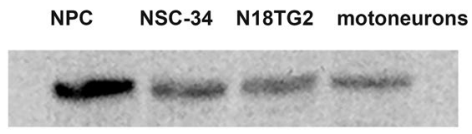

GS

c

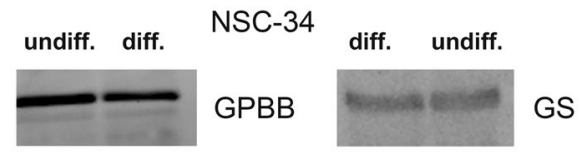

d

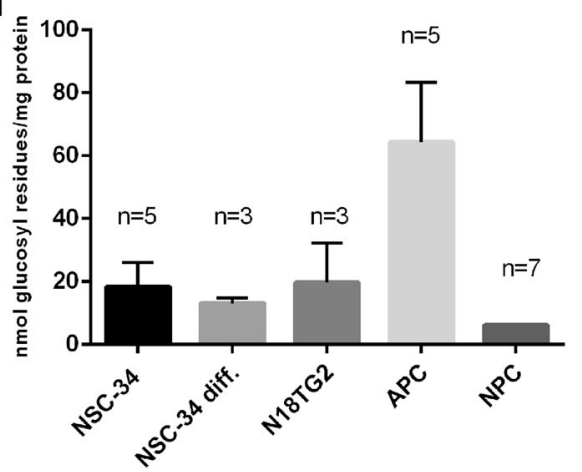

Fig. 1 Key-enzymes of glycogen metabolism and glycogen content in cultured mouse neural cell types. a,b Western blot analysis for the detection of glycogen phosphorylase brain isoform (GPBB) and glycogen synthase (GS) in homogenates of NSC-34 and N18TG2 cells compared to neuronal primary cultures (NPC) and pure motoneuron cultures. c Western blot analysis of differentiated NSC-34 cells compared to undifferentiated cultures. Amount of protein applied per lane: a $10 \mu \mathrm{g}$, b $5 \mu \mathrm{g}$, c $30 \mu \mathrm{g}$ for GPBB and $15 \mu \mathrm{g}$ for GS. d Quantitative determination of glycogen. Data represent mean values $\pm S D$ of $n$ experiments each performed in triplicate. Values for NPC were taken from the literature. Here, error bar could not be indicated because individual values were not reported [9]

enzymes (Fig. 1c). Both cell lines do not express GP MM (data not shown).

We determined the glycogen content of confluent NSC-34 and N18TG2 cells under culture conditions: DMEM, 10\% fetal calf serum, $25 \mathrm{mM}$ glucose. Glycogen values varied widely between experiments, but were comparably high in both cell types (Fig. 1d). They exceeded those found for primary neuronal cultures. Differentiation of NSC-34 (3\% FCS, $25 \mathrm{mM}$ glucose) did not influence the glycogen content.

\section{The Glycogen Content of NSC-34 Cells is Dependent on the Glucose Concentration, but not on the Presence of FCS}

Because $25 \mathrm{mM}$ glucose and the presence of $10 \%$ FCS (culture conditions) do not reflect metabolic conditions, we examined the influence of glucose concentration and FCS on the glycogen content of NSC-34 neurons. In contrast to primary neuronal cultures [9] we found a decline in glycogen content with declining glucose concentration (Fig. 2a). Absence of FCS did not significantly alter the glycogen content (Fig. 2b) as also demonstrated in differentiated NSC-34 cultures (data not shown).

\section{Glycogen in NSC-34 Cells is Readily Mobilizable by Glucose Deprivation, but not by Hormones Stimulating cAMP Formation and by Methoxamine}

Next, we studied the dynamics of NSC-34 glycogen stores under glucose deprivation, a metabolic situation in which the AMP concentration raises. After $2 \mathrm{~h}$ on glucose-free DMEM, the glycogen store is depleted but can be replenished by a subsequent $2 \mathrm{~h}$ incubation with $5 \mathrm{mM}$ glucose. This repletion results in a glycogen content exceeding the basal value (Fig. 3a).

In cultured astrocytes, glycogen is mobilized by vasointestinal peptide, noradrenaline, adenosine and dibutyryl-cAMP (dbcAMP) [19]. Noradrenaline and adenosine did not lower the glycogen content of NSC-34 cells. dbcAMP, a membrane-permeable stable cAMP analog, elicited a moderate decline in glycogen content (Fig. 3b). Methoxamine, an activator of the phosphatidyl-inositol cascade, has also been shown to promote glycogenolysis in cultured astrocytes [20]. In NSC-34 cells, methoxamine does not significantly lower the glycogen content (Fig. 3c).

\section{The Glycogen Content of NSC-34 Neurons is Influenced by the $\mathrm{K}^{+}$-Concentration}

Neuronal activity and some pathological situations stimulate glycogenolysis in brain slices by raising extracellular $\left[\mathrm{K}^{+}\right]$ and intracellular $\left[\mathrm{Ca}^{2+}\right][21,22]$. This glycogenolysis had been attributed to astroglial cells. In order to look whether a high $\mathrm{K}^{+}$concentration influences neuronal glycogenolysis in cultures, we exposed NSC- 34 cells to $\mathrm{K}^{+}$concentrations reached at neuronal activity $(10 \mathrm{mM})$ or under pathological conditions $(40 \mathrm{mM})$. The glycogen content was lowered slightly at $\left[\mathrm{K}^{+}\right]$of $10 \mathrm{mM}$ and significantly at $40 \mathrm{mM}$ (Fig. 4).

\section{Cellular Metabolic Stress Induces Glycogen Degradation in NSC-34 and N18TG2 Neurons}

Under hypoxic conditions ( $1 \% \mathrm{O}_{2}$ instead of $\left.21 \%\right)$, cultured primary neurons degrade their glycogen stores by the action of GP [9]. In order to investigate whether this might also apply to NSC-34 and N18TG2 cells, we exposed the cultures to hypoxic conditions. After $4 \mathrm{~h}$ of hypoxia, both cell lines showed a significant reduction of their glycogen content 


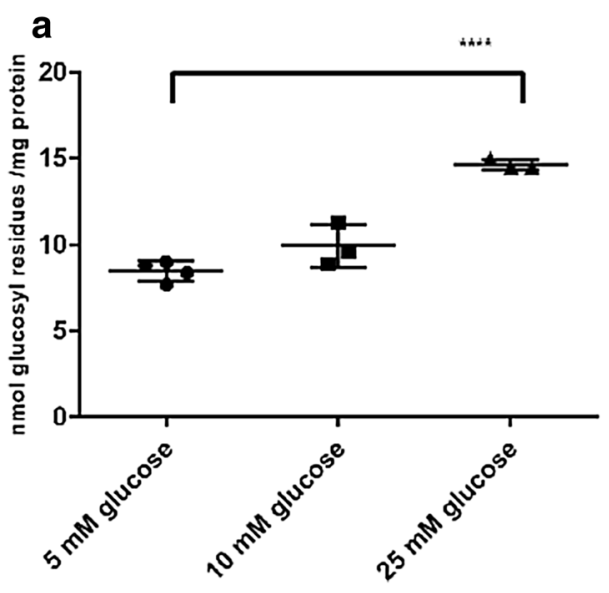

Fig. 2 Influence of glucose concentration and FCS on the glycogen content of NSC-34 cultures. a Cells were cultured to confluency in $\mathrm{DMEM} / 10 \% \mathrm{FCS} / 25 \mathrm{mM}$ glucose, the medium was changed to media containing 5,10 and $25 \mathrm{mM}$ glucose, respectively, and cells b

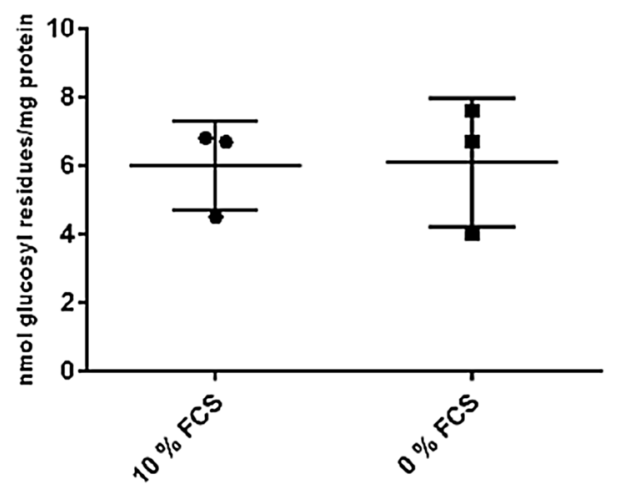

cultured for another $60 \mathrm{~min}$. b Cells were cultured to confluency, then switched to DMEM/25 mM glucose with or without FCS and cultured for another $60 \mathrm{~min}$. Significant differences are as indicated: $* * * * \mathrm{p}<0.0001$
Fig. 3 Influence of glucose deprivation and modulators on the glycogen content of NSC-34 cells. a Confluent cells were switched to glucose-free DMEM/-FCS and cultured for $12 \mathrm{~h}$ (depletion). For repletion, cells were switched to DMEM/25 mM glucose/-FCS for $2 \mathrm{~h}$. b, c Confluent cells were switched to DMEM/5 $\mathrm{mM}$ glucose/-FCS for $4 \mathrm{~h}$. Then, modulators were added to a concentration of $100 \mu \mathrm{M}$ and cells cultured for $30 \mathrm{~min}$. Significant differences are as indicated: *p $<0.05 ; * * \mathrm{p}<0.01$; $* * * \mathrm{p}<0.001$

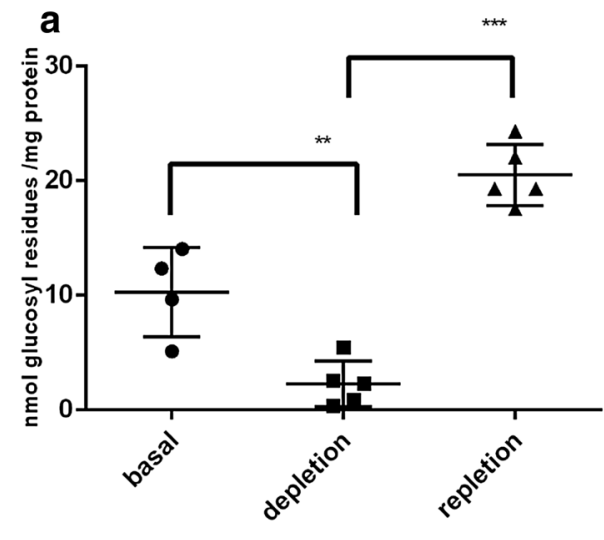

c

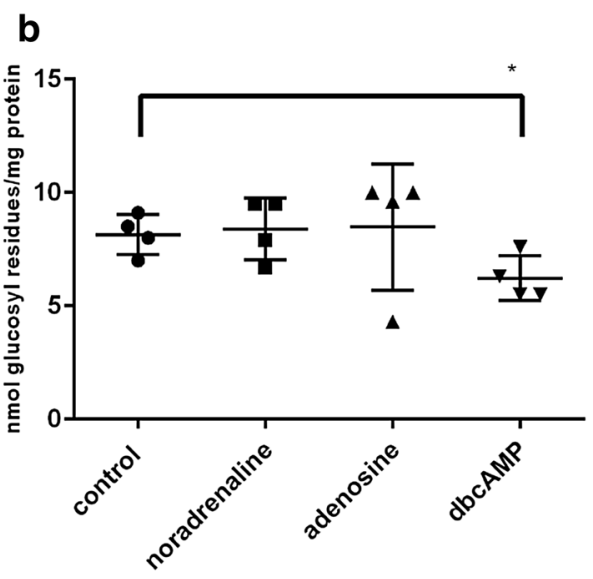

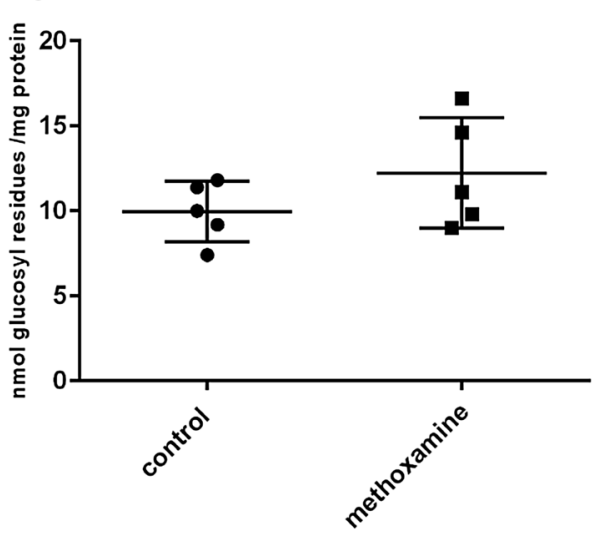

compared to normoxic conditions (Fig. 5a,b). The viability of the cells was $100 \%$.

In astroglia-rich primary cultures, glycogen is degraded following administration of peroxides [23]. In order to look whether this metabolic stress situation is also a trigger for neuronal glycogen degradation, we exposed the cultures to mild oxidative stress $\left(500 \mu \mathrm{M} \mathrm{H}_{2} \mathrm{O}_{2}\right.$ for $30 \mathrm{~min}$ and $2 \mathrm{~h}$, respectively). In NSC-34 and N18TG2, glycogen was reduced in a time-dependent manner (Fig. 5c, d). Viability was not influenced. 


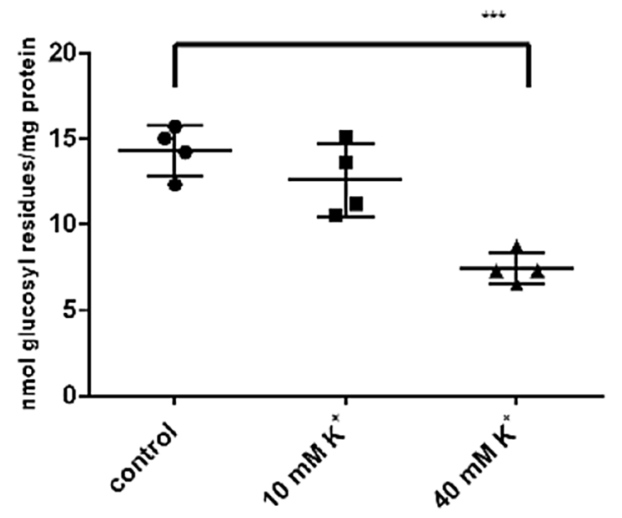

Fig. 4 Influence of elevated $\left[\mathrm{K}^{+}\right]$on the glycogen content of NSC-34 cells. Confluent cells were cultured in DMEM/5 mM glucose/-FCS for $4 \mathrm{~h}$ and then switched to the indicated $\left[\mathrm{K}^{+}\right]$for $30 \mathrm{~min}$. Significant differences are as indicated: $* * * \mathrm{p}<0.001$

Deviation from the physiological value of $\mathrm{pH}$ is another form of metabolic stress. We therefore exposed the cell lines to moderate acidic $\mathrm{pH}$ conditions. Lowering the $\mathrm{pH}$ from 7.4 to 7.0 did not result in glycogen degradation. Acidification to $\mathrm{pH} 6.5$, however, reduced the glycogen content in NSC-34 and in N18TG2 (Fig. 5e, f). Viability was slightly reduced at $\mathrm{pH} 6.5(95 \%)$.

\section{Astrocyte Primary Cultures and Metabolic Stress}

Astrocytes in culture react with glucose degradation on hypoxia and oxidative stress analogously to neuronal cell lines (Fig. 6a,b). Lowering the $\mathrm{pH}$ from 7.4 to 7.0 leads to glycogen degradation, but in contrast to the cell lines, further lowering the $\mathrm{pH}$ to 6.5 reconstituted the glycogen store (Fig. 6c).

\section{Knockdown of GP BB Abolishes Glycogen Degradation Under Metabolic Stress}

In order to demonstrate that the glycogenolytic answer to metabolic stress is due to GPBB action, we performed siRNA knockdown of GPBB in NSC-34 cells and APC with subsequent exposure to oxidative stress. After GPBB knockdown, glycogen content was elevated compared to untransfected cells and cells transfected with non-targeting siRNA (Fig. 7a). Exposure to oxidative stress did not reduce the glycogen in cells transfected with siRNA but in cells transfected with NT siRNA (Fig. 7b, c). The Western blot signal for GPBB was reduced in cells transfected with siRNA (Fig. 7d).

\section{Discussion}

Brain glycogen is mainly located in astrocytes. The low amount of neuronal glycogen has long been overlooked. An active glycogen metabolism and a functional role for glycogen in neurons could only be demonstrated recently after the upcoming of sensitive methods. Our studies with two neuronal cell lines support these findings. In these cells, glycogen is degraded under conditions of metabolic stress thus confirming the results of Saez et al. [9] with cortical neuronal cultures.

Because of the high immunoreactivity of GPBB in spinal motor neurons $[7,8,10]$ it seemed a logical idea that a cell line derived from these cells might have a higher glycogen content than cortical neurons. This was indeed the case: In the hybrid cell line NSC-34 we measured a glycogen content that was three-fold higher than that of cortical neurons. In our experiments, differentiation did not influence neither the enzymatic pattern of GPBB and GS nor the glycogen content indicating that glycogen metabolism is not a privilege of differentiated cells.

The parent tumor cell line N18TG2 had a similar glycogen content and enzymatic machinery than the motor neuron/tumor cell hybrid, suggesting that glycogen metabolism is not an exclusive genetic contribution of the motor neuron parent. This suggests a general importance of neuronal glycogen. Glycogen content of the neuronal cell lines exceed that of cortical neurons. This may be due to the specific metabolic situation of spinal motor neurons as well as of tumor cells.

In order to elucidate the function(s) of neuronal glycogen, we studied the influence of metabolic stress situations on the glycogen content. The simplest form of metabolic stress is glucose deprivation. We could demonstrate that the glycogen is rapidly mobilized under glucose deprivation, and that the store is replenished after glucose repletion showing a super compensation already demonstrated for cortical neurons after hypoxia [9].

Another situation of stress is hypoxia. It has been demonstrated that under hypoxic conditions, glycogenolysis ${ }^{\circ} \mathrm{C}$ curs though extracellular glucose concentration is high, and prevents cortical neurons from cell death [9]. Under these conditions, cellular uptake of glucose and its metabolism via glycolysis is obviously not sufficient to meet the requirements of the neurons. Degradation of glycogen, in contrast, leads to a faster energy availability. We found that NSC-34 and N18TG2 but also APC, reacted upon hypoxia with glycogen mobilization.

Reactive oxygen species (ROS) are continuously generated in cells during oxidative metabolism. Elevated levels of ROS are a hallmark in nerve cell injuries because they can lead to cell death via diverse oxidative and 
Fig. 5 Influence of metabolic stress on the glycogen content of NSC-34 (a, c, e) and N18TG2 (b, d, f) cells Confluent cells were switched to DMEM/5 mM glucose/-FCS for $4 \mathrm{~h}$ and then exposed to the stress situations. a, b hypoxia stress: Cells were exposed for $\mathrm{O}_{2}, 5 \% \mathrm{CO}_{2}, 94 \% \mathrm{~N}_{2}$ ), control cells were kept under normoxic conditions $\left(21 \% \mathrm{O}_{2}\right)$. c, $\mathbf{d}$ oxidaa concentration of $500 \mu \mathrm{M}$ and cells kept for 30 and $120 \mathrm{~min}$, respectively. e, f acidic $\mathrm{pH}$ : Cells were incubated for $1 \mathrm{~h}$ on a $37{ }^{\circ} \mathrm{C}$ water bath in a buffer containing $20 \mathrm{mM}$ HEPES with Earle's salts and $5 \mathrm{mM}$ glucose, adjusted to the $\mathrm{pH}$ values indicated. Significant differences are as indicated: $* \mathrm{p}<0.05$; $* * \mathrm{p}<0.01 ; * * * \mathrm{p}<0.001$ $4 \mathrm{~h}$ to hypoxic conditions ( $1 \%$ tive stress: $\mathrm{H}_{2} \mathrm{O}_{2}$ was added to
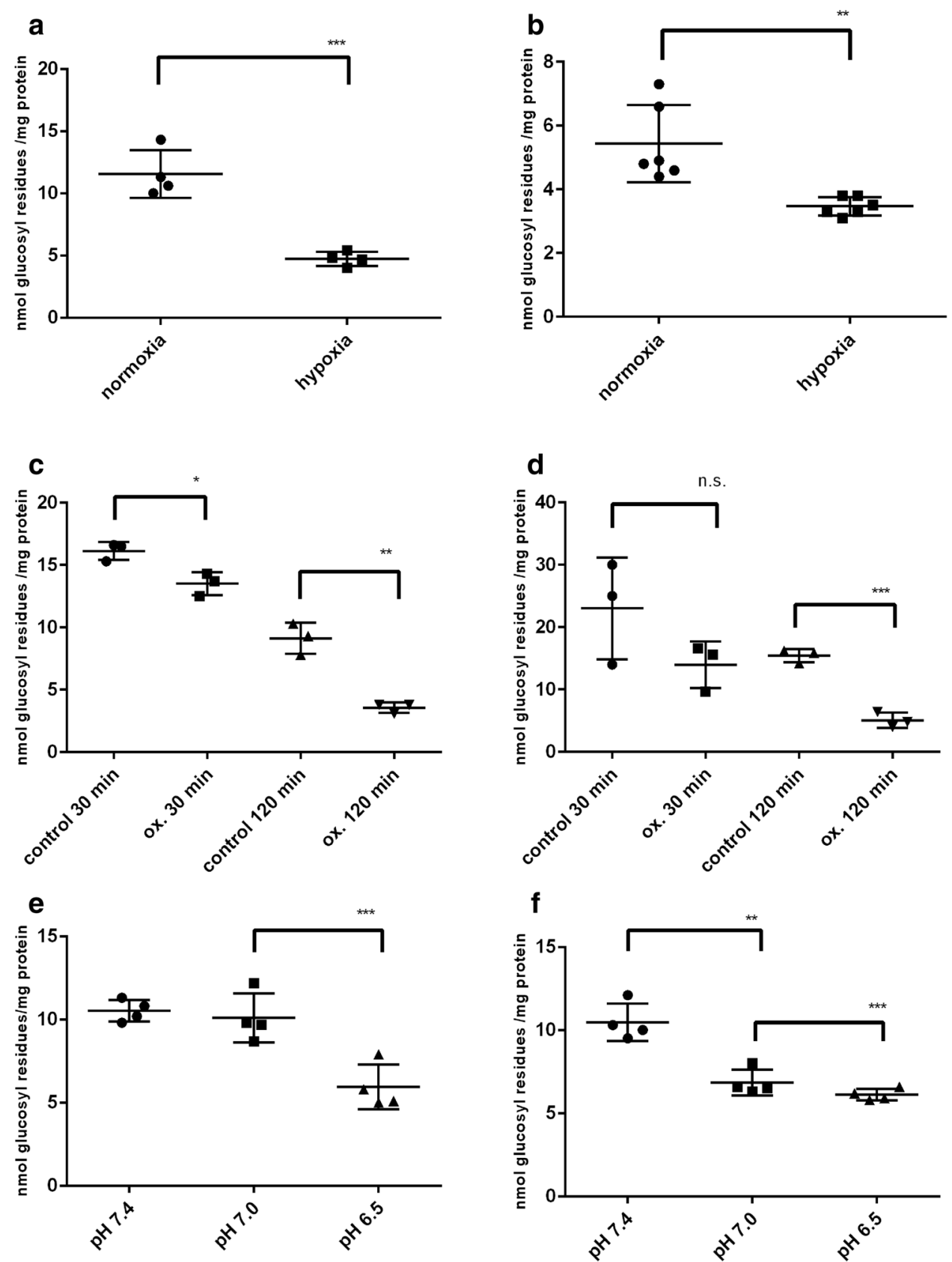

peroxidative reactions $[24,25]$. It has already been demonstrated that in cultured astrocytes, glycogen was mobilized during the disposal of peroxides [23]. This glycogenolysis was interpreted as a source for glucose-6-phosphate, the substrate fueling the pentose phosphate shunt which is necessary for the generation of NADPH. NADPH, in turn, is needed for the glutathione redox cycling system in cellular peroxide detoxification. Our findings that mild oxidative stress led to glycogenolysis in neuronal cell lines, might be a hint to a similar mechanism in highly sensitive neurons.
Another situation of metabolic stress is acidification. Maintenance of the extracellular $\mathrm{pH}$ within strict boundaries is crucial for normal cell function. Extracellular acidity is observed in ischemia and acute inflammation, but is also a hallmark of solid tumors giving those cells an advantage over normal cells. It could be demonstrated that in HEK cells extracellular $\mathrm{pH}$ lowering induced mitochondrial dysfunction, protein carbonylation and increased ROS levels [26]. In melanoma cells, extracellular acidity increases intracellular $\mathrm{Ca}^{2+}$ - levels [27]. We could find that in NSC-34 and N18TG2 cells pH lowering to 6.5 resulted in glycogenolysis. 
Fig. 6 Influence of metabolic stress on the glycogen content of APC. a hypoxia; $\mathbf{b}$ oxidative stress; c acidic $\mathrm{pH}$. Cultures were used for experiments after 2 weeks of culturing and experiments carried out as described for the cell lines. Significant differences are as indicated: $* \mathrm{p}<0.05 ; * * * \mathrm{p}<0.001$ $* * * * \mathrm{p}<0.0001$

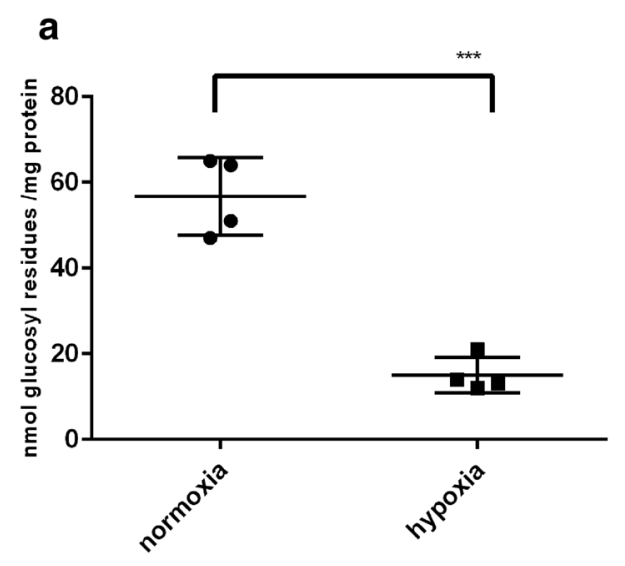

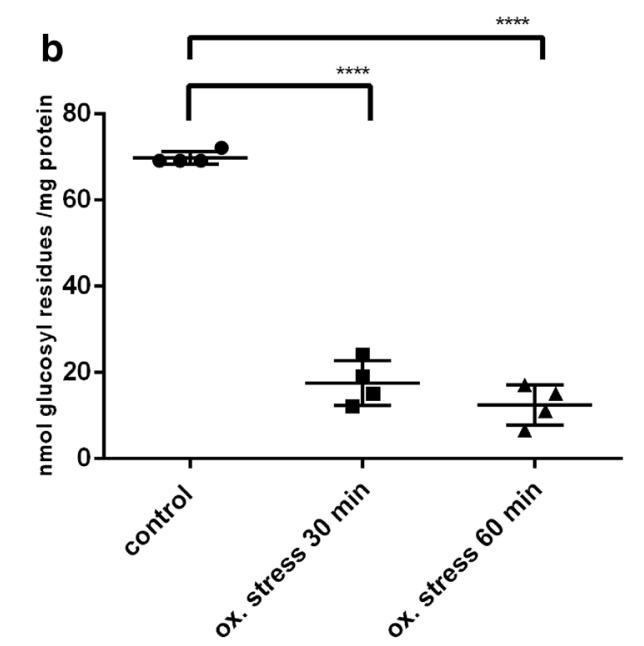

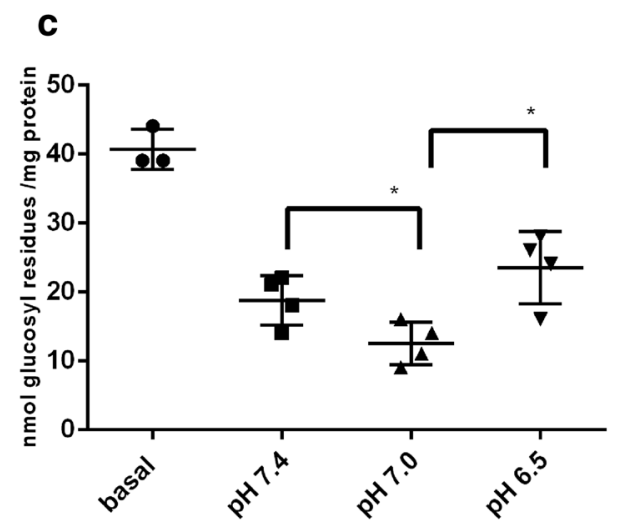

Neuronal excitability and neurotransmission induce $\mathrm{pH}$ alterations which, in turn, regulate $\mathrm{pH}$ sensitive transport systems [28] involving energy consumption. Rapid energy supply by glycogen degradation might play a role in situations of extracellular acidosis. Also, elevated ROS levels might request activation of the pentose phosphate shunt. In addition, elevated intracellular $\left[\mathrm{Ca}^{2+}\right]$ can activate GP by a $\mathrm{Ca}^{2+}$ - dependant mechanism as demonstrated in brain slices [22]. In APC, we observed glycogenolysis upon $\mathrm{pH}$ lowering from 7.4 to 7.0. Lowering the $\mathrm{pH}$ to 6.5 , however, resulted in a reconstitution of the glycogen content to values exceeding that at $\mathrm{pH} 7.4$, a super-compensation that may serve as an anticipatory mechanism of further stress.

We tried to get insight into the mechanism by which glycogen degradation is triggered in neurons. GP can be activated by two mechanisms, (1) covalent phosphorylation triggered by hormones via the cAMP cascade, and (2) allosteric control by AMP. GPMM is primarily activated by the first mechanism, while GPBB is more susceptible to the second mechanism [29]. Selective knockdown of the two isoforms in cultured astrocytes confirmed these differences [17]. We found that in neuronal cell lines neither noradrenaline nor adenosine lowered the glycogen level. dbcAMP, a cell-permeable cAMP analog that circumvents the receptor binding step and acts directly on protein kinase $\mathrm{A}$, shows a moderate effect. $\mathrm{IP}_{3}$ can also activate glycogenolysis by binding to $\alpha_{1}$-receptors which leads to activation of proteinkinase $\mathrm{C}$ and elevated intracellular $\mathrm{Ca}^{2+}{ }_{-}$-levels. In our cell models, methoxamine, an activator of the $\mathrm{IP}_{3}$-induced glycogenolysis in astrocytes [20], did not show a significant effect. Glucose deprivation, however, led to glycogenolysis. Knockdown of GPBB reduced the stress-induced glycogenolysis. These results indicate that neuronal glycogenolysis is primarily induced by the energy status of the cell.

Neuronal activity raises the extracellular $\mathrm{K}^{+}$- concentration to $5-12 \mathrm{mM}$. As could be demonstrated with cortical slices, this leads to the opening of voltage-gated $\mathrm{Ca}^{2+}$ -channels and elevated intracellular $\mathrm{Ca}^{2+}$-concentrations resulting in glycogenolysis [22]. Under pathological conditions like hypoxia, spreading depression or ischemia, extracellular $\mathrm{K}^{+}$- concentrations up to $40 \mathrm{mM}$ have been reported [21]. In cultured astrocytes, glycogenolysis is triggered by store-operated $\mathrm{Ca}^{2+}$ - entry [17]. In NSC-34 cells, elevation of extracellular $\mathrm{K}^{+}$resulted in glycogenolysis. probably by a $\mathrm{Ca}^{2+}$-dependent mechanism. $\mathrm{Ca}^{2+}$ stimulates glycogenolysis by activation of phosphorylase kinase. Because GPBB is weakly activated by phosphorylation, elevated cytosolic $\mathrm{Ca}^{2+}$ might induce glycogenolysis by increasing the AMP concentration. This is the case when energy consumption and thus ATP hydrolysis take place. ATP is needed for maintaining ion 
Fig. 7 siRNA knockdown of GPBB in NSC-34 cells and APC and influence of oxidative stress on the glycogen content after siRNA knockdown.

Cells were transfected with either siRNA or NT siRNA and subsequently exposed to oxidative stress. a NSC-34, knockdown without oxidative stress. b NSC-34, knockdown with subsequent exposure to oxidative stress. c APC, knockdown with subsequent exposure to oxidative stress. d Western blot analysis for demonstration of knockdown in NSC-34 cells and APC. For NSC-34, $30 \mu \mathrm{g}$ of protein were applied in each lane; for APC, $6 \mu \mathrm{g}$ of protein were applied. Significant differences are as indicated: $* \mathrm{p}<0.05 ; * * * \mathrm{p}<0.001$
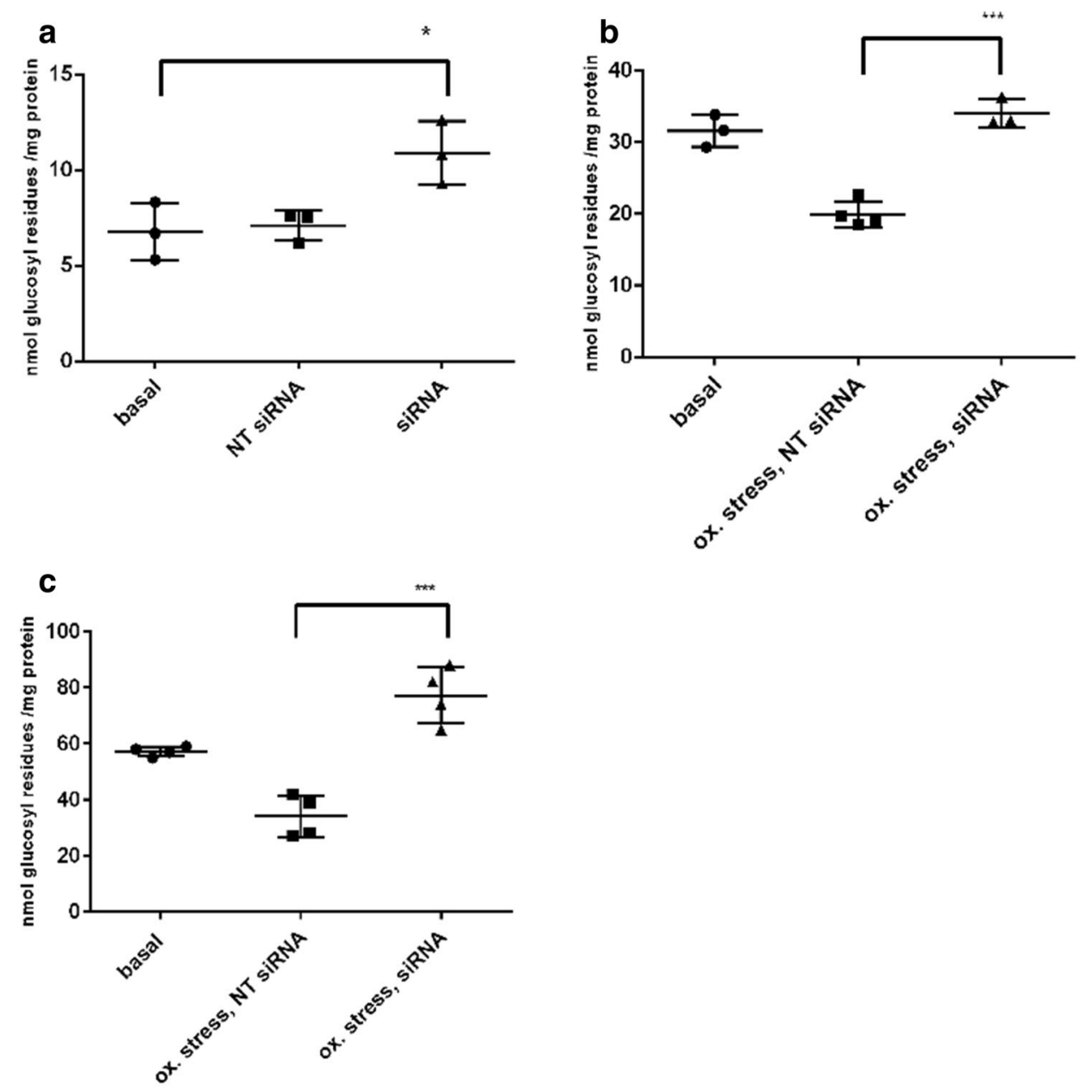
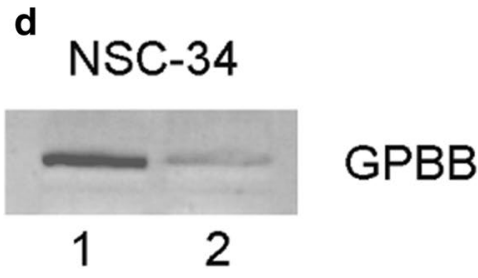

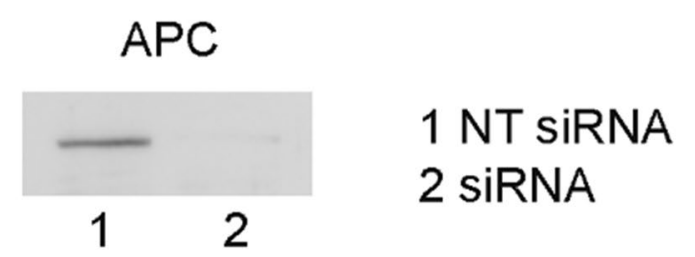

gradients after $\mathrm{Ca}^{2+}$ - influx [17]. In this metabolic situation, glycogenolysis is the fastest way to replenish ATP stores.

\section{Conclusions}

Here, we could demonstrate the presence of glycogen and an active glycogen metabolism in neuronal cell lines. Because we found no difference between the motor neuron/neuroblastoma hybrid NSC-34 and the tumor cell line N18TG2, the glycogen metabolizing machinery seems not to be a unique tool of spinal cord motor neurons. In our models, glycogenolysis is elicited by situations of metabolic stress thus pointing to a so far neglected relevant role of neuronal glycogen in general. Neurons express, in contrast to astrocytes, only the GPBB isoform which is supposed to be primarily activated by the AMP level. In our studies, hormones activating covalent phosphorylation of GP had no glycogenolytic effect. This supports the proposed functional differences of the GP isoforms.

Acknowledgements The authors thank Joan J. Guinovart for the kind gift of a test sample of glycogen synthase antibody and S. Jablonka for the samples of motoneuron homogenates for Western blot analysis.

Funding Open Access funding enabled and organized by Projekt DEAL. No funding, grants or other support was received.

Data Availability Data will be made available on reasonable request.

\section{Declarations}

Conflict of interest The authors declare that there are no financial or proprietary interests in any material discussed in this article. 
Ethical Approval Animal experiments were carried out according to the Law of animal experimentation issued by the German parliament and to the European Communities Council Directive.

Open Access This article is licensed under a Creative Commons Attribution 4.0 International License, which permits use, sharing, adaptation, distribution and reproduction in any medium or format, as long as you give appropriate credit to the original author(s) and the source, provide a link to the Creative Commons licence, and indicate if changes were made. The images or other third party material in this article are included in the article's Creative Commons licence, unless indicated otherwise in a credit line to the material. If material is not included in the article's Creative Commons licence and your intended use is not permitted by statutory regulation or exceeds the permitted use, you will need to obtain permission directly from the copyright holder. To view a copy of this licence, visit http://creativecommons.org/licenses/by/4.0/.

\section{References}

1. Cahill GF Jr (1976) Starvation in man. Clin Endocrinol Metab 5:397-415

2. Sickmann HM, Walls AB, Schousboe A, Bouman SD, Waagepetersen HS (2007) Functional significance of brain glycogen in sustaining glutamatergic neurotransmission. J Neurochem 109:80-86

3. Duran J, Saez I, Gruart A, Guinovart JJ, Delgado-Garcia JM (2013) Impairment in long-term memory formation and learningdependent synaptic plasticity in mice lacking glycogen synthase in the brain. J Cereb Blood Flow Met 33:550-556

4. Hertz L, Chen YE (2018) Glycogenolysis, an astrocyte-specific reaction, is essential for both astrocyte and neuronal activities involved in learning. Neurosci 370:27-36

5. Kong J, Shepel PN, Holden CP, Mackiewicz M, Pack AI, Geiger JD (2002) Brain glycogen decreases with increasing periods of wakefulness: implications for homeostatic drive to sleep. J Neurosci 22:5581-5587

6. Vilchez D, Ros S, Cifuentes D, Pujadas L, Vallès J, Garcia-Fojeda B, Criado-Garcia O, Fernándes-Sánches E, Mendrano-Fernándes I, Dominguez J, Garcia-Roch M, Soriano E, Rodriguez de Córdoba S, Guinovart JJ (2007) Mechanism suppressing glycogen synthesis in neurons and its demise in progressive myoclonus epilepsy. Nat Neurosci 10:1407-1413

7. Pfeiffer-Guglielmi B, Fleckenstein B, Jung G, Hamprecht B (2003) Immunocytochemical localization of glycogen phosphorylase isozymes in rat nervous tissues using isozyme-specific antibodies. J Neurochem 85:73-81

8. Pfeiffer-Guglielmi B, Franke M, Reichenbach A, Hamprecht B (2007) Glycogen phosphorylase isozymes and energy metabolism in the rat peripheral nervous system - an immunocytochemical study. Brain Res 1136:20-27

9. Saez I, Duran J, Sinadinos C, Beltran A, Yanes O, Tevy MF, Martinez-Pons C, Milán M, Guinovart JJ (2014) Neurons have an active glycogen metabolism that contributes to tolerance to hypoxia. J Cereb Blood Flow Met 34:945-955

10. Pfeiffer-Guglielmi B, Dombert B, Jablonka S, Hausherr V, van Thriel C, Schöbel N, Jansen RP (2014) Axonal and dentritic localization of mRNAs for glycogen-metabolizing enzymes in cultured rodent neurons. BMC Neurosci 15:70-81

11. Duran J, Guinovart JJ (2015) Brain glycogen in health and disease. Mol Aspects Med 46:70-77

12. Gardiner TA, Canning P, Tipping N, Archer DB, Stitt AW (2015) Abnormal glycogen storage by retinal neurons in diabetes. Invest Ophthal Vis Sci 56:808-818
13. Gentry MS, Guinovart JJ, Minassian BA, Roach PJ, Serratosa JM (2018) Lafora disease offers a unique window into neuronal glycogen metabolism. J Biol Chem 293:7117-7125

14. Cashman NR, Durham HD, Blusztajn JK, Oda K, Tabira T, Shaw IT, Dahrouge S, Antel JP (1992) Neuroblastoma $\times$ spinal cord (NSC) hybrid cell lines resemble developing motor neurons. Dev Dyn 194:200-221

15. Eggett CJ, Crosier S, Manning P, Cookson MR, Menzies FM, McNeil CJ, Shaw PJ (2000) Development and characterization of a glutamate-sensitive motor neurone cell line. J Neurochem 74:1895-1902

16. Matusica D, Fenech MP, Rogers ML, Rush RA (2008) Characterization and use of the NSC-34 cell line for study of neurotrophin receptor trafficking. J Neurosci Res 86:553-565

17. Müller MS, Pedersen SE, Walls AB, Waagepetersen HS, Bak LK (2015) Isoform-selective regulation of glycogen phosphorylase by energy deprivation and phosphorylation in astrocytes. GLIA 63:154-162

18. Zhu A, Romero R, Petty HR (2009) An enzymatic fluorometric assay for glucose-6-phosphate: application in an in vitro Warburglike effect. Anal Biochem 388:97-101

19. Sorg O, Magistretti PJ (1991) Characterization of the glycogenolysis elicited by vasoactive intestinal peptide, noradrenaline and adenosine in primary cultures of mouse cerebral cortical astrocytes. Brain Res 563:227-233

20. Sorg O, Magistretti PJ (1992) Vasoactive intestinal peptide and noradrenaline exert long-term control on glycogen levels in astrocytes: blockade by protein synthesis inhibition. J Neurosci 12:4923-4931

21. Sykova E (1983) Extracellular $\mathrm{K}^{+}$accumulation in the central nervous system. Prog Biophys Mol Biol 42:135-189

22. Hof PR, Pascale E, Magistretti $P(1988) \mathrm{K}^{+}$at concentrations reached in the extracellular space during neuronal activity promotes a $\mathrm{Ca}^{2+}$-dependent glycogen hydrolysis in mouse cerebral cortex. J Neurosci 8:1922-1928

23. Rahman B, Kussmaul L, Hamprecht B, Dringen R (2000) Glycogen is mobilized during the disposal of peroxides by cultured astroglial cells from rat brain. Neurosci Lett 290:169-172

24. Cookson MR, Shaw P (1999) Oxidatve stress and motor neuron disease. Brain Pathol 9:165-186

25. Hachem LD, Mothe AJ, Tator CH (2015) Effect of BDNF and other potential survival factors in models of in vitro oxidative stress on adult spinal cord-derived neural stem/progenitor cells. Biores Open Access 4(1):146-159

26. Teixeira J, Basit F, Swarts HG, Forkink M, Oliveira PJJ, Willems PHGM, Koopman WHJ (2018) Extracellular acidification induces ROS- and mPTP-mediated death in HEK293 cells. Redox Biol 15:394-404

27. Kato Y, Ozawa S, Tsukuda M, Kubota E, Miyazaki K, St-Pierre Y, Hata RI (2007) Acidic extracellular $\mathrm{pH}$ increases calcium influxtriggered phospholipase $\mathrm{D}$ activity along with acidic sphingomyelinase activation to induce matrix metalloproteinase-9 expression in mouse metastatic melanoma. FEBS J 274:3171-3183

28. Lee BO, Jung YS (2017) Sustained intracellular acidosis triggers the $\mathrm{Na}^{+} / \mathrm{H}^{+}$exanger- $1 \mathrm{Ac}$ in glutamate excitotoxicity. Biomol Ther (Seoul) 25:593-598

29. Crerar MM, Karlsson O, Fletterick RJ, Hwang PK (1995) Chimeric muscle and brain glycogen phosphorylase defined protein domains governing isozyme-specific responses to allosteric activation. J Biol Chem 270:13748-13756

Publisher's Note Springer Nature remains neutral with regard to jurisdictional claims in published maps and institutional affiliations. 